prof. dr hab. inż. Jerzy Madej

dr hab. ini. Marian Medwid, prof. nadzw.

dr Wtodzimierz Stawecki

Instytut Pojazdów Szynowych „TABOR”

\title{
Nowy mechanizm zmiany rozstawu kół w pojazdach szynowych dla szerokości toru 1435 - 1520
}

\begin{abstract}
Niniejsze opracowanie ogólnie dotyczy nowej koncepcji pojazdów dla zmiennego rozstawu szyn. W Instytucie Pojazdów Szynowych ,TABOR” opracowano nowe oryginalne rozwiqzanie rozsuwanego zestawu kót dla zastosowań trakcyjnych $i$ tocznych wewnatrz zarzqdów UIC oraz ОСЖД $i$ pomiędzy nimi. Artykut prezentuje techniczna strukture i projekt mechanizmu oraz zasade jego pracy ( $w$ obrębie stanowiska przestawczego) uwzględniajac obydwa kierunki przestawcze: „,tam” $i$,,z powrotem”. Proces przestawczy zostat przetestowany na redukcyjnym modelu $w$ skali ( 1:12).
\end{abstract}

\section{Wstęp}

Liczne rozwiązania konstrukcyjne zestawów kół pojazdów szynowych, przystosowanych do ruchu w torach o zmiennym rozstawie szyn, są współcześnie dość powszechnie znane i stosowane [1]; [2]. Znane i stosowane są konstrukcje pojazdów szynowych z kołami osadzonymi na niezależnych, lecz względem siebie współosiowych i rozsuwanych odcinkach osi (np. Talgo III [3]). Jednak $\mathrm{w}$ dostępnej literaturze technicznej oraz $w$ doniesieniach medialnych najbardziej szczegółowo zostały opisane liczne zestawy kół poosiowo rozsuwanych wzdłuż wspólnej osi wirującej lub niewirującej [4-10] oraz [14]. Ogólnie, dla przypadku osi niedzielonej, w poniższej Tabeli 1 wyodrębniono trzy odmiany konstrukcji zestawów rozsuwanych.

Do znanych konstrukcji z grupy 1 , należy zaliczyć: O.G.I. (Hiszpania); TG 14 (dawny ZSRR); DR AG/RAFIL V (Niemcy) [1]; SUW 2000 (Polska) [11] oraz system Japoński [14].

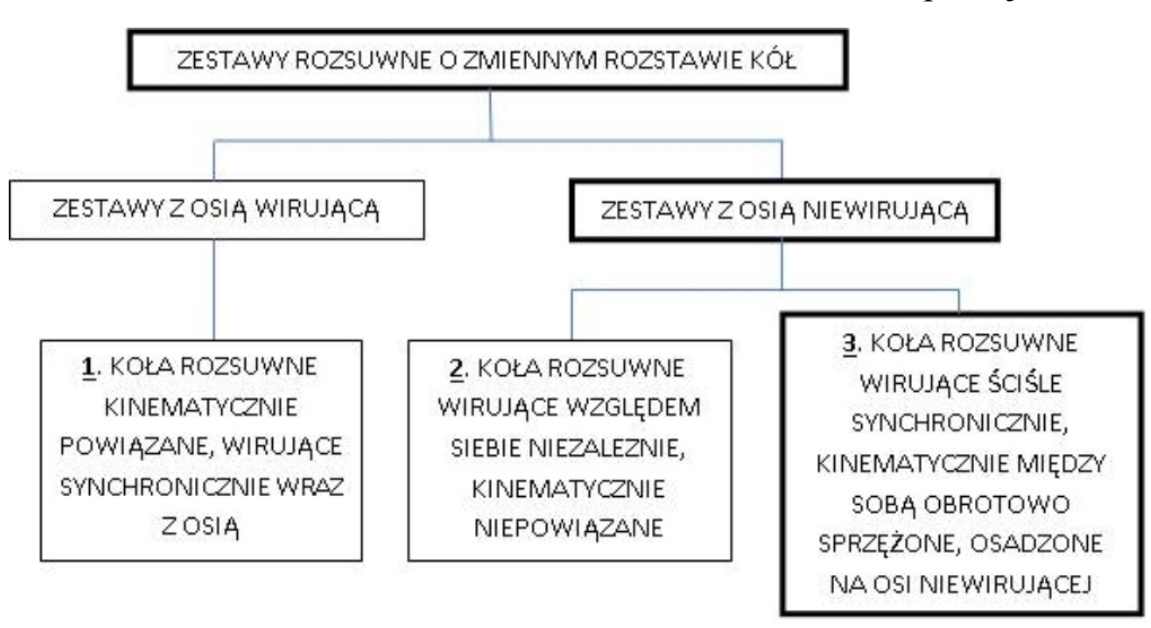

Do znanych konstrukcii $\mathrm{z}$ grupy 2 , należy zaliczyć: Vevey (Szwajcaria); BDZ (Bulgaria); RTRI (Japonia); [1n]

Do znanych konstrukcji $\mathrm{z}$ grupy 3, należy zaliczyć konstrukcje polskie chronione patentami B1 201613 oraz 202614. [12] i [13].

\section{Przedmiot opracowania}

Przedmiotem niniejszego opracowania jest - należący do grupy 3 - nowy mechanizm zmiany rozstawu kół biegowych w zestawie pojazdu szynowego, $\mathrm{z}$ osią niewirująca, lecz obrotowo - wahliwą. Zasada pracy mechanizmu została w dalszym ciagu zilustrowana rysunkami 1 i 2 . Rozwiązanie tego mechanizmu jest chronione przez Urząd Patentowy RP [15].

Obydwa wirujące koła zestawu, ułożyskowane względem swych niewirujących piast wewnętrznych, zostały względem siebie sztywno kinematycznie sprzężone w kierunku obrotowym. Piasty kół są osadzone na wspólnej osi, roboczo niewirującej, za pośrednictwem

ROZSUWNE

Tabela 1 
przeciwzwojnych połączeń śrubowych tak, że przy przestawczych obrotowo - wahliwych przemieszczeniach osi doznają one względem siebie ściśle określonych, programowanych, przeciwsobnych przemieszczeń poosiowych. Roboczo niewirująca oś zestawu, podczas procesu przestawczego doznaje określonego, sterującego wahliwego przemieszczenia obrotowego dzięki wymuszonym ruchom dźwigni przestawczej, sterowanej od strony toru przez specjalne torowe zaczepy.

Piasty obydwóch kół biegowych zostały sprzężone wysuwnie z korpusami łożysk osiowych tak, iż mają jedynie możliwość wzajemnego przemieszczania się w kierunku poosiowym w odpowiedniej synchronizacji z kątowymi przemieszczeniami wahliwej osi w procesie przestawczym.

Przedmiot niniejszego opracowania został zilustrowany rysunkami. Rysunek 1 przedstawia poosiowy przekrój przez mechanizm zmiany rozstawu kół w dwóch położeniach, odpowiadających pracy zestawu w torze o szerokości $1435 \mathrm{~mm}$ oraz $1520 \mathrm{~mm}$. Natomiast Rysunek 2 przedstawia szczegóły dotyczące zasad odpowiedniego skojarzenia poosiowego przesuwu pojedynczego koła przy współpracy z dźwignią przestawczą 6 , w zależności od kierunku zwojów śruby w określonym połączeniu osi $1 \mathrm{z}$ piastą 3 koła biegowego.
Roboczo niewirująca oś zestawu 1 została osadzona $\mathrm{w}$ korpusach prowadników osi $2 \mathrm{w}$ taki sposób, że ma możliwość dokonywania jedynie wahliwych sterujących przemieszczeń obrotowych. Na osi 1, pomiędzy korpusami prowadników osiowych 2 , znajdują się śrubowo osadzone piasty 3 kół biegowych 4 zestawu. Piasty 3 mogą się przemieszczać względem prowadników osi 2 jedynie poosiowo, bez możliwości obrotu. Koła biegowe 4 zostały obrotowo ułożyskowane na piastach 3 za pośrednictwem łożysk 5 . Koła biegowe 4 są względem siebie obrotowo bez luzu sprzężone za pomocą wysuwnego wału $\mathrm{W}, \mathrm{z}$ możliwością jedynie wzajemnych przemieszczeń poosiowych względem siebie. Podczas ruchu zestawu w obrębie przestawczego stanowiska torowego oś 1 doznaje wymuszonego wahliwego przemieszczenia obrotowego dzięki obrotowi osadzonej na jej końcu dźwigni przestawczej 6, wyposażonej obustronnie w czopy 7 , które to czopy, zaczepiając o odpowiednio usytuowane torowe zaczepy przestawcze 13, wymuszają obrót dźwigni przestawczej o pewien, ściśle określony kąt, dzięki czemu rozstaw kół biegowych 4 zmienia się w zaprogramowanym kierunku. Obydwie piasty 3 kół biegowych 4 są osadzone na osi $1 \mathrm{w}$ skojarzeniach śrubowych 15 przeciwzwojnych kierunkowo. Podczas powrotnego ruchu zestawu w obrębie stanowiska przestawczego

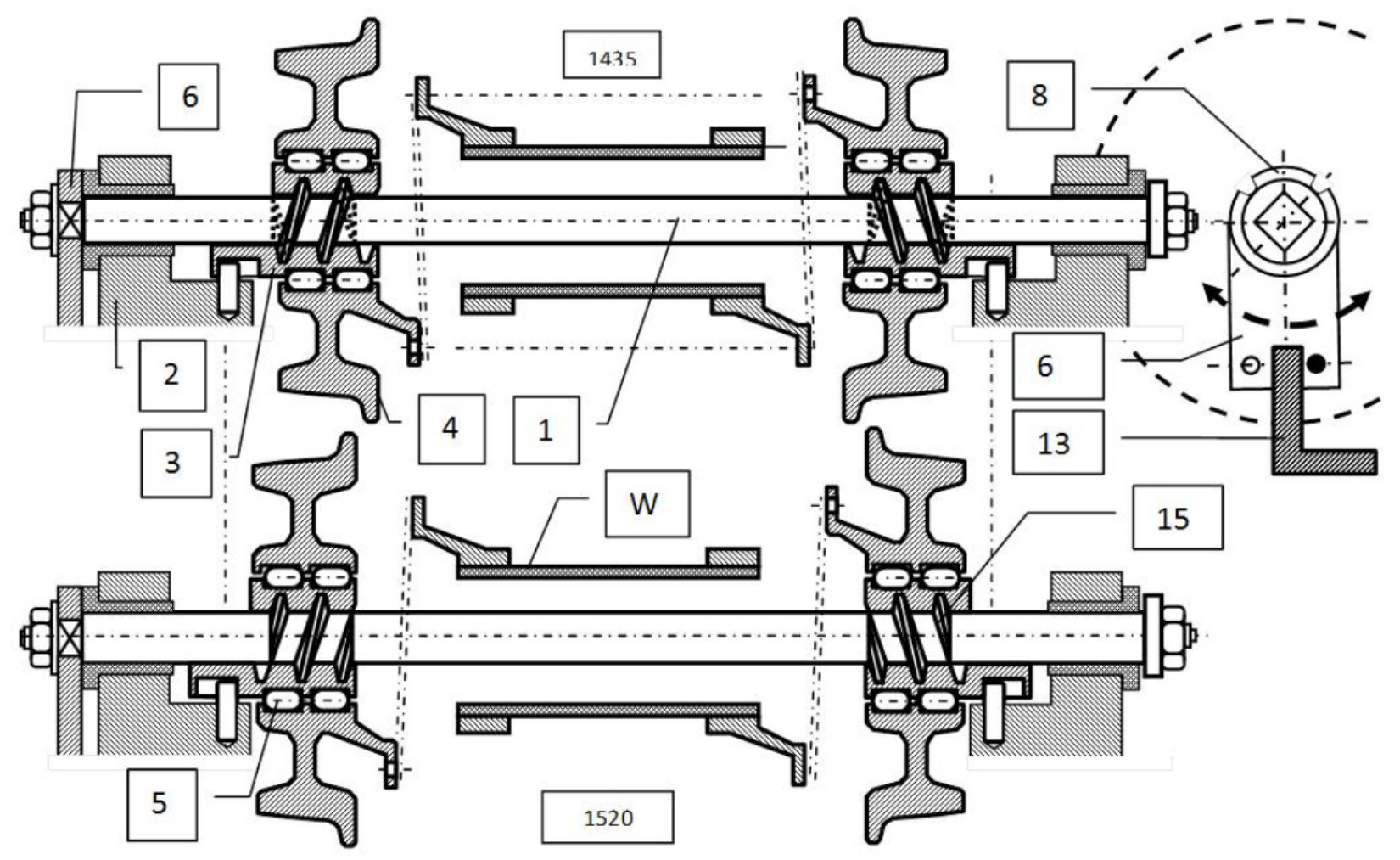

Rysunek 1. Mechanizm zmiany rozstawu w dwóch położeniach odpowiadających pracy zestawu w torze o szerokości $1435 \mathrm{~mm}$ (u góry) oraz $1520 \mathrm{~mm}$. 


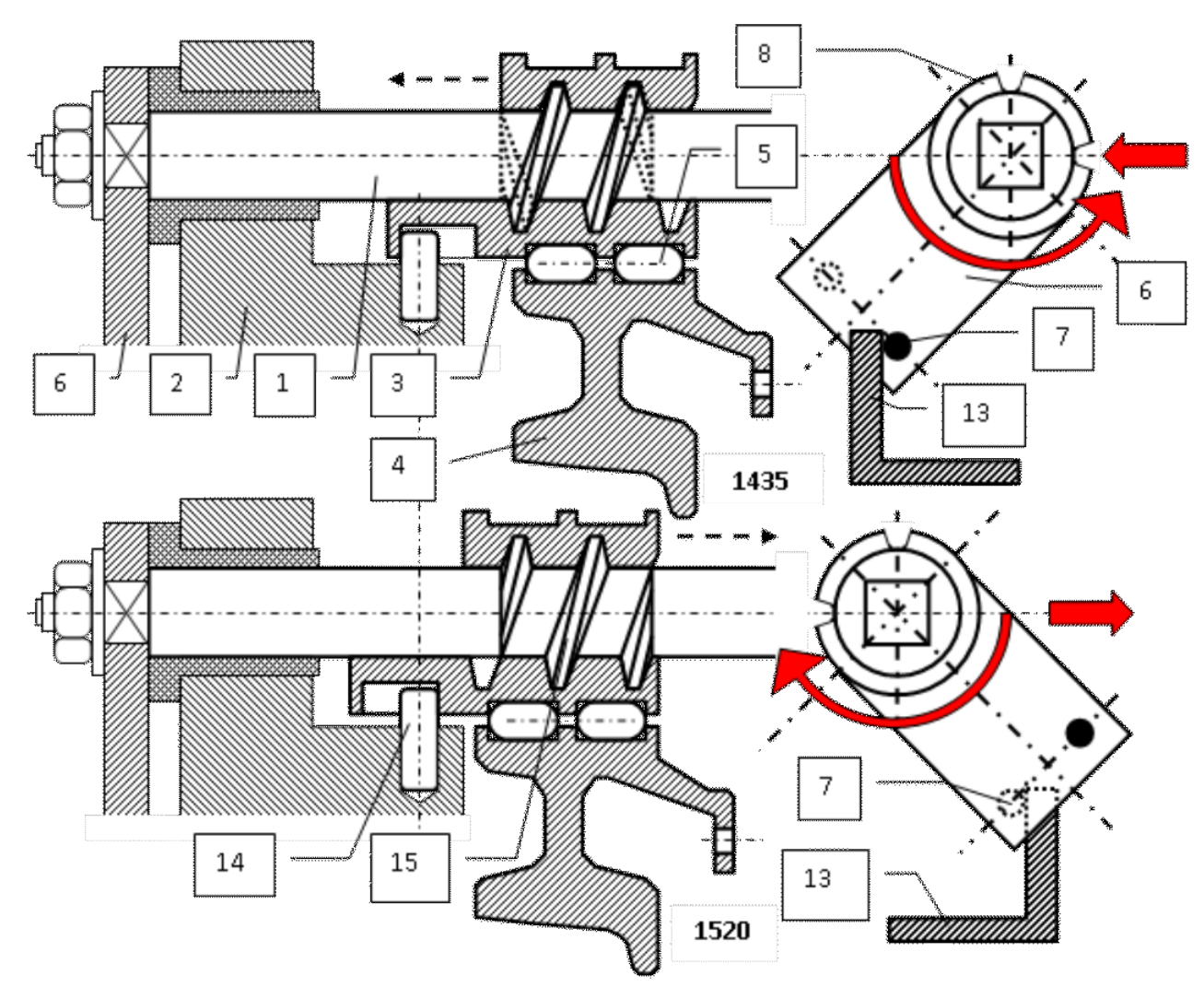

Rysunek 2. Przyporządkowanie rozrządu położeń dźwigni przestawczej i rozstawu kół biegowych.

dźwignia przestawcza 6 zaczepia o ,powrotny” zaczep torowy i rozstaw kół biegowych zostaje odpowiednio zmieniony w kierunku odwrotnym, według planowego programu pracy układu.

Oś 1 zestawu jest sztywno połączona z dźwignią przestawczą 6 i odpowiednio skojarzona $\mathrm{z}$ kierunkiem zwojów śruby $15 \mathrm{w}$ taki sposób, że ruch zestawu w torze na kierunku $1435 \rightarrow 1520$ wywoła rozsunięcie piast 3 z kołami 4, co zilustrowano na rysunkach 1 i 2 w części górnej.

Obydwa czopy 7, „dolny” i ,górny” dźwigni 6, znajdują się (wystają) po jej przeciwnych stronach.

Podczas ruchu zestawu w torze (rysunek 2 górny ruch w lewo) na kierunku przestawczym $1435 \rightarrow 1520$, dolny czop 7 dźwigni 6, po swojej stronie napotka torowy zaczep dźwigni 13 i obróci tę dźwignię zgodnie z kierunkiem strzałki. „Dolny” czop dźwigni 6, (nadal w fazie przestawczej $1435 \rightarrow 1520$ ), znajdując się po innej stronie dźwigni 6 niż czop górny, w zakończeniu fazy przyjmie położenie górne. Dzięki te$\mathrm{mu}, \mathrm{w}$ chwili zakończenia fazy przestawczej $1435 \rightarrow$ 1520, po drugiej stronie dźwigni zostaje przygotowany inny czop, jako ponownie ,dolny”, dla przestawienia zestawu w kierunku powrotnym. Taki kierunek powrotny ilustruje dolna część rysunku (ruch w prawo).
Kinematyka współpracy dźwigni przestawczej $z$ zaczepem torowym

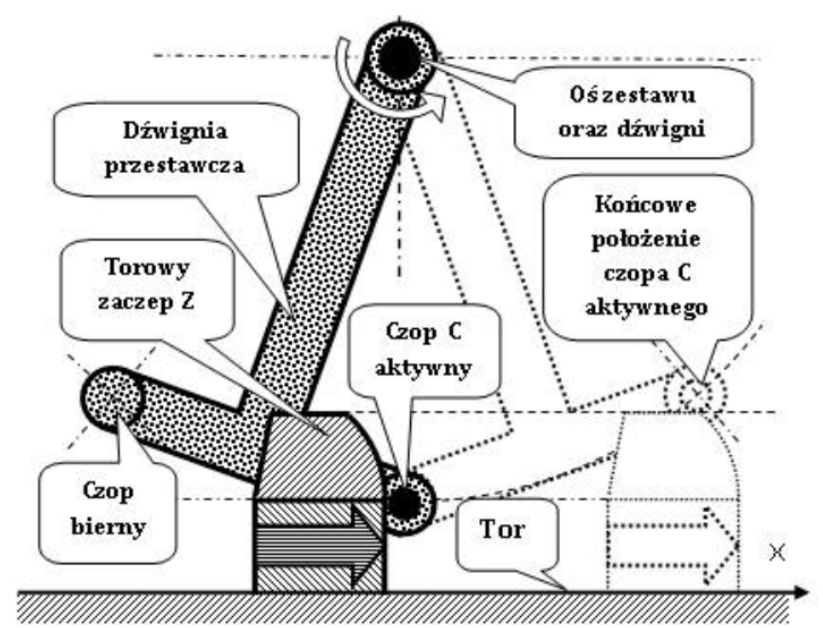

Rysunek 3. Początkowa faza przestawcza: Czop aktywny C dźwigni przestawczej wchodzi w kontakt $\mathrm{z}$ torowym zaczepem $\mathrm{Z}$. Widok w układzie współrzędnych poruszających się wraz z pojazdem. 


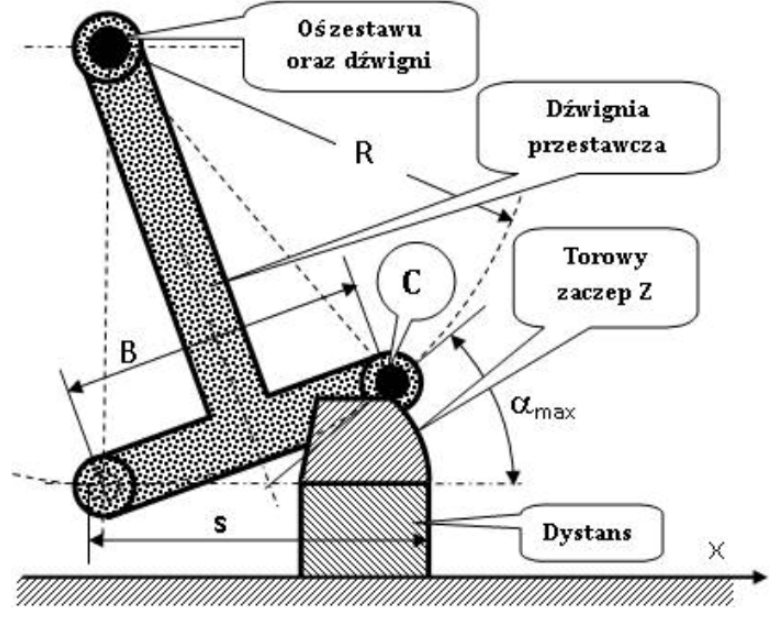

Rysunek 4. Końcowa faza przestawcza: Czop aktywny C wspiął się na najwyższy punkt zaczepu torowego $\mathrm{Z}$, przy czym dźwignia przestawcza osiagnęła docelowe położenie kątowe. Warunki ruchu identyczne jak dla rysunku 3. Drugi czop (bierny w omawianej relacji przestawczej) przeszedł na pozycję przygotowaną do przestawienia powrotnego.

Zasadę budowy dźwigni przestawczej ilustruje załączona fotografia redukcyjnego $(\sim 1: 12)$ modelu mechanizmu wykonanego w metalu.

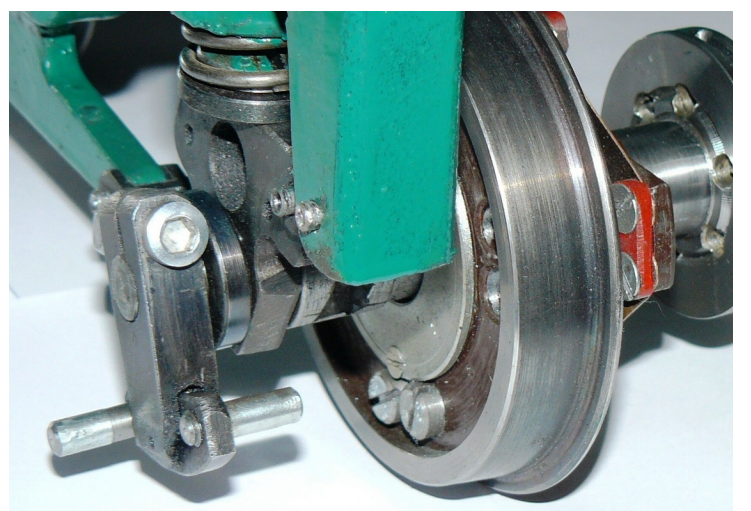

Fot. 1. Widok modelu dźwigni przestawczej wyposażonej w dwa czopy umieszczone po jej obydwóch stronach

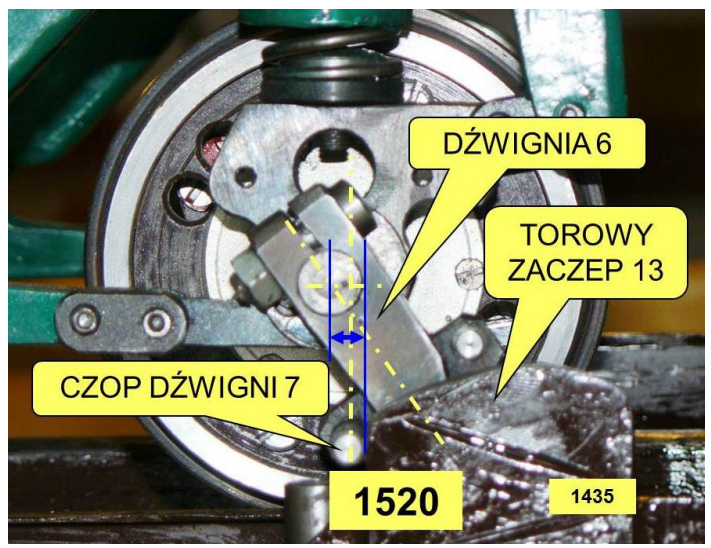

Fot. 2. Ilustracja wpływu średnicy czopa dźwigni oraz początkowego jej położenia na całkowitą drogę zmiany rozstawu kół

$Z$ powyższego widzimy, że współpraca dźwigni przestawczej $\mathbf{6}$ z zaczepem torowym $\mathbf{Z}$ wywiera zasadniczy wpływ na przebieg procesu rozsuwania kół zestawu. W dalszym ciagu wyznaczymy takie techniczne warunki tej współpracy, że wahliwy ruch obrotowy osi $\mathrm{w}$ procesie przestawczym będzie się odbywać z ustaloną prędkością kątową.

$\mathrm{Na}$ rysunku 5 przedstawiono strukturalny schemat współpracy czopa $\mathbf{C}$ dźwigni przestawczej $\mathbf{D}$ z torowym zaczepem $\mathbf{Z}$.

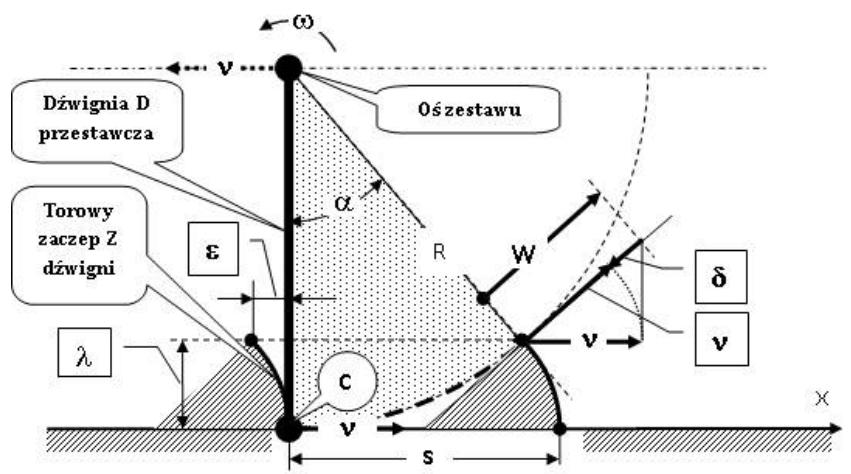

Rysunek 5. Współpraca czopa C dźwigni przestawczej D z torowym zaczepem $\mathbf{Z}$ podczas zmiany rozstawu kół zestawu.

Analitycznie rozważymy przypadek konstrukcyjnie uproszczony, gdy czop C dźwigni przestawczej D, kontaktujący się $\mathbf{z}$ torowym zaczepem $\mathbf{Z}$, jest traktowany jako punkt. (Wytrasowanie kształtu torowego zaczepu dźwigni przy uwzględnieniu skończonego wymiaru średnicy czopa C i dobranie wysokości skrajniowego dystansu jest warsztatowym zadaniem elementarnym).

Jeżeli podczas ruchu zestawu $\mathrm{w}$ torze ze względną $\mathrm{i}$ ustaloną prędkością $\mathbf{v}=\mathbf{c o n s t}$., czop $\mathbf{C}$ dźwigni przestawczej $\mathbf{D}$ nagle, w chwili $\mathbf{t}=\mathbf{0}$, przy początkowym kącie obrotu osi $\boldsymbol{\alpha}=\mathbf{0}$, napotkałby pionową przeszkodę, to początkowa prędkość obrotowa $\omega_{\mathrm{o}}$ osi zestawu wyniosłaby:

$$
\omega_{(t=0)}=\omega_{o}=\frac{v}{R} ; \quad v=\text { const }
$$

Jednak w miarę równomiernego narastania $\mathrm{w}$ czasie $\mathbf{t}$ względnego przemieszczenia $\mathbf{s}=\mathbf{v} \cdot \mathbf{t}$, oraz przy rosnącej przy tym wartości kąta $\alpha$, przy zachowywaniu niezakłóconego kontaktu czopa $\mathbf{C}$ z przeszkodą pionową, prędkość obrotowa $\omega$ osi zestawu, ze względu na zwiększoną prędkość obwodową czopa, narastałaby do wartości $\mathbf{W}(\alpha)$ :

$$
\omega(\alpha)=\frac{v}{R \cos \alpha}=\frac{W}{R} ; \quad \text { gdzie }: W=\frac{v}{\cos \alpha} ;
$$

Każdy punkt profilu zaczepu torowego $\mathbf{Z}$ względem osi zestawu porusza się z prędkością $v$. Po przebyciu przez zestaw $\mathrm{w}$ torze drogi $\mathbf{s}=\boldsymbol{v} \cdot \mathbf{t}$, gdy dźwignia przyjęła położenie $\alpha$, prędkość obrotowa $\omega$ dźwigni osiaga wartość opisaną wzorem (2).

W przypadku zaczepu $\mathbf{Z}$ wykonanego w postaci pionowej przeszkody przed czopem $\mathbf{C}$, na mocy wzoru (2) mielibyśmy niepożądany przyrost prędkości obrotowej osi: 


$$
\lim _{\alpha \rightarrow \pi / 2} \omega=\infty,
$$

Zatem należy tak neutralizować narastanie prędkości obrotowej osi przez odpowiednie ukształtowanie profilu natarcia torowego zaczepu $\mathbf{Z}$, aby wywołać ujemną obwodową prędkość korekcyjną $\delta(\alpha)$, ustalającą prędkość obrotu osi według rysunku 5 oraz według wzoru (2). Moduły wektorów prędkości obwodowych, zgodnie z rysunkiem 5, spełniają warunek (3).

$$
|W|=|v|+|\delta|
$$

Przemieszczenia $\lambda$ i $\varepsilon$ są ściśle przyporządkowane wartości $\alpha$ kąta obrotu osi, a tym samym także przyporządkowane względem drogi s, przebytej przez oś wzdłuż toru:

$$
\begin{aligned}
& \varepsilon=s-R \sin \alpha \\
& \lambda=R(1-\cos \alpha)
\end{aligned}
$$

zatem:

$$
\frac{\varepsilon}{\lambda}=\frac{\frac{s}{R}-\sin \alpha}{1-\cos \alpha} ; \quad s<<R
$$

Zauważmy, że kiedy $\mathbf{s}=\mathbf{0}$, to także $\boldsymbol{\alpha}=\mathbf{0}$, oraz $\frac{d \varepsilon}{d \lambda}=0$; Rzutując moduł korekcyjnego wektora $\delta$ na oś $\mathbf{X}$ otrzymujemy:

$$
\varepsilon=\delta \cos \alpha=(W-v) \cos \alpha=v(1-\cos \alpha)
$$

Punkt skrzyżowania się stycznych do okregu, przyłożonych na krańcach wycinka tego okręgu (Rys.5) ograniczonego kątem $\alpha$, wraz ze środkiem okręgu wyznacza linię ścisłego podziału tego wycinka na dwie jednakowe części. Porównując zapisy $\lambda$ i $\varepsilon$ we wzorach (4) i (6), zgodnie z rysunkiem widzimy, że występuje geometryczne podobieństwo wycinków dwóch okręgów, ograniczonych ramionami kąta $\alpha$ : wycinka okręgu o promieniu $\mathbf{R}$, oraz wycinka okręgu o promieniu s/2. Według rysunku 5 pola zakropkowane i zakreskowane są geometrycznie podobne.

Zatem, posługując się zależnością (4), możemy następująco zapisać analityczną zasadę tego podobieństwa, które zapewnia stałość prędkości $\omega$ obrotu osi, przy stałej prędkości $v$ przejazdu:

$$
\frac{\lambda}{R \sin \alpha}=\frac{\varepsilon}{\lambda}, \text { albo }: \frac{\lambda}{s-\varepsilon}=\frac{\varepsilon}{\lambda},
$$

czyli ostatecznie:

$$
\lambda=\sqrt{\varepsilon(s-\varepsilon)}
$$

Dzięki ściśle określonemu ukształtowaniu krawędzi natarcia torowego zaczepu $Z$, zarówno prędkość obrotowa osi jak i prędkość zmiany rozstawu kól w procesie przestawczym są stałe.
Na koniec należy zauważyć, że na mocy wzorów (7) i (8), profil torowego zaczepu $\mathbf{Z}$ jest opisany klasycznym równaniem okręgu, zatem profil ten, dla każdej wartości przebytej drogi s, ma zarys łuku kołowego, co też sprzyja łatwości wykonania profilu zaczepu:

$$
\lambda^{2}+\varepsilon^{2}=\varepsilon \cdot s
$$

\section{Podsumowanie}

W przedstawionym opracowaniu zaprezentowano schemat i zasadę budowy nowego mechanizmu zmiany rozstawu kół w pojazdach szynowych dla szerokości toru $1435 \leftrightarrow 1520$, w którym rozsuwane koła zostały obrotowo osadzone na osi niewirującej, lecz wirują ściśle synchronicznie, gdyż są kinematycznie między sobą obrotowo sprzężone. Omówiono ogólnie proces rozsuwania kół a także szczegółowo przeanalizowano ten proces $\mathrm{z}$ uwzględnieniem warunku stałej prędkości rozsuwania kół $\mathrm{w}$ obrębie stanowiska przestawczego.

Zagadnienia konstrukcyjne, dotyczące bezpieczeństwa pozycjonowania rozstawu kół, zostaną omówione $\mathrm{w}$ oddzielnym opracowaniu.

\section{LITERATURA:}

[1] Kostro Janusz: Analiza porównawcza istniejacych konstrukcji zestawów kót o zmiennym rozstawie kót. Warszawa, 2001.

Analiza [1] została sporzadzona na podstawie nastepujacych 14 prac: [a] Salinger W.: Spurwechselradsatze. Rail International - Schenen der Welt 03/2000; [b] Gomez J.L.L.: TALGO - wutomatisches Umspursystem fur den Personen - und Guterverkehr. Eisenbahningenieur 12/1997; [c] Garde R.: A Roues a Ecartement Variable. R.G.C.F. 1974 s. 423-424. [d] Raeber V.: L'Essieu Ferroviaire a Ecartement Variable Systeme VEVEY. R.G.C.F. 1974 ..424-428. [e] Rurio D.R.: L'Essieu a Ecartement Variable Systeme O.G.I. R.G.C.F. 1974 s. 428-430. [f] Essieu a Ecartement Variable de la DR. R.G.C.F. 1969 s. 5758; Ig] La Premiere Liaison Ferroviwire Voyageurs Directe Entre Madrid et Paris R.G.C.F. 1969 s.108109. [h] Japanese Develop First Gauge-Adap-table EMU. Intern. Rail. Journal. 01/1999; Ii] Suwalski R.M.: SUW 2000 - Wózki towarowe I osobowe w automatycznym ruchu przestawczym 1435/1520mm TTS 7-8/2000. [j] Szadur L.A.: Wagony- Konstrukcija, teorija i rasczot. Moskva, Transport 1973. [k] Dimitrov Ż.H. Kardkow T.D.: Wagony. Dierżawno Izdat. Sofia 1988. [I] UIC Code 510-4 Guterwagen. Fahrwerke mit Spurwechsel 1435/1520. Empfehlungen fur bilateralen Abkommen. [m] System solutions for automatic transition from standard gauge to broad gauge. Prospekt DB Cargo. [n] Masakatsu Sakai, Kazuhiro Oda: Gauge Change Train. Japanese Railway Engineering 143/2001.

[2] http://en.wikipedia.org/wiki/Variable_gauge

[3] http://en.wikipedia.org/wiki/Talgo 
[4] http://www.ipaustralia.com.au/applicant/patentestalgo-sl/patents.AU2011201895/

[5] (Talgo)

http://www.youtube.com/watch?feature $=$ endscreen\& $v=y 8 N 7 I k w 87 t M \& N R=1 /$

[6] (Talgo) http://www.youtube.com/watch? $v=U i q U w q 5 p i R U$

[7] (Talgo) http://www.youtube.com/watch? $v=Z i H 4 k t 14 y G w$

[8] (Talgo)

http://www.youtube.com/watch? $v=8 c 7 e h H e l 2 z 8$

[9] (Talgo)

http://www.youtube.com/watch? $v=K i S o 8 F W 9 e R 0$

[10] (Talgo)

http://www.youtube.com/watch?v=FB4Owz3YWlo

[11] Suwalski Ryszard: Polski system samoczynnej zmiany rozstawu kót do wagonów towarowych, osobowych $i$ pojazdów trakcyjnych $w$ transkontynentalnym ruchu kolejowym. Dyrekcja Kolejowych Przewozów Towarowych CARGO Wydziat Rozwoju, Kraków
[12] Patent B1 Nr. 201613 z dnia 30.04.2009 WUP 04/09. Zestaw kołowy do pojazdów szynowych o zmiennym rozstawie kót. Madej J., Medwid M., Stawecki Wt., Pawlak Z.:

[13] Patent B1 Nr. 202614 z dnia 31.07.2009 WUP 07/09. Zestaw kołowy do pojazdów szynowych o zmiennym rozstawie kót. Madej J., Medwid M., Stawecki Wt., Pawlak Z.:

[14] Akira Takeshima (Deputy Director Technological Development Office, Railway Bureau Ministry of Land Infrastructure, Transport and Tourism) DEVELOPMENT OF THE GAUGE CHANGE TRAIN SYSTEM IN JAPAN (Internet).

[15] Zgloszenie Patentowe Instytutu Pojazdów Szynowych TABOR Nr. P-402514 z dnia 22-01-2013: Madej Jerzy, Medwid Marian, Stawecki Włodzimierz, Czerwiński Jarosław: Mechanizm zmiany rozstawu kół $w$ pojazdach szynowych dla różnych szerokości toru. 